\title{
Estudo da correlação da susceptibilidade magnética e da radiação gama com a mineralização de cobre em corpos máficos-ultramáficos no norte da Bahia
}

Robson Santos da Purificação* (IGEO/UFBA), Daniel Conceição dos Santos (IGEO/UFBA), Florivaldo Oliveira Sena (SERVIGEO) e Marcos Alberto Rodrigues Vasconcelos (IGEO/UFBA)

Copyright 2016, SBGf - Sociedade Brasileira de Geofísica

Este texto foi preparado para a apresentação no VII Simpósio Brasileiro de Geofísica, Ouro Preto, 25 a 27 de outubro de 2016. Seu conteúdo foi revisado pelo Comitê Técnico do VII SimBGf, mas não necessariamente representa a opinião da SBGf ou de seus associados. É proibida a reprodução total ou parcial deste material para propósitos comerciais sem prévia autorização da SBGf.

\section{Abstract}

This study aims to correlate magnetic susceptibility and gammaspectrometry data to copper mineralization. Measurements have been made in 18 drill cores from Lagoa da Mina and Cercado Velho targets, located in northern Bahia. They comprise a total of 2451.96 meters of material with $6 \mathrm{~cm}$ diameter. The results of the analysis are shown as geophysical profiles comparing lithology mineralization content and physical property measurement and through statistical analysis. The Pearson coefficient for each hole indicating was estimated in order to observe whether there is a correlation between copper and physical properties for each profile.

\section{Introdução}

A área de estudo deste trabalho está localizada na região cuprífera do Vale do Curaçá no norte da Bahia. Ela é denominada de fazenda Angico e possui dois alvos, um ao norte com nome de Lagoa da Mina e outro ao sul com nome de Cercado Velho. Os alvos são corpos máficos e ultramáficos mineralizados integrantes do complexo Caraíba, que segundo Teixeira (1997) é formado principalmente por um conjunto de gnaisses de alto grau metamórfico e granitoides diversos, com a ocorrência de inúmeros corpos máficos e ultramáficos, alguns portadores de mineralizações de cobre de caráter comercial como é o caso dos alvos objeto deste trabalho.

As mineralizações de cobre no Vale do Curaçá ocorrem predominantemente nos corpos notitico-piroxeniticos, que são metamorfitos que em geral apresentam grau de metamorfismo concordante com as rochas encaixantes (D'el Rey Silva, 1984). As mineralizações de sulfetos são principalmente de calcopirita, pirita, bornita e raramente pirrotita que ocorrem principalmente nas rochas noríticaspiroxeniticas, acompanhando o contato destas litologias, no corpo Lagoa da Mina, as mineralizações ocorrem principalmente nos noritos em forma de grãos disseminados e de microlentes preenchendo juntas e fissuras. No corpo Cercado Velho as mineralizações ocorrem de forma alongada e tabular refletindo a forma do corpo máfico-ultramáfico. As rochas mineralizadas acham-se frequentemente alteradas hidrotermalmente e algumas vezes totalmente cisalhadas (Delgado e Souza, 1975).
Delgado e Souza (1975) sugeriram que a mineralização nos alvos da área de estudo deste trabalho poderiam apresentar boa correlação com a susceptibilidade magnética, no entanto, não foram feitos trabalhos com este objetivo na região, desta forma este trabalho se propõe a identificar se existe de fato uma boa correlação entre susceptibilidade magnética e 0 teor de mineralização de cobre em rochas máficas e ultramáficas no norte da Bahia e ainda verificar a existência deste mesmo tipo de correlação com a radiação gama. Para isso foram efetuadas medidas em testemunhos de sondagem em 18 furos. Metade dos furos analisados estão localizados na porção norte da área de estudo deste trabalho denominada Lagoa da Mina - LM, enquanto a outra metade localiza-se na porção sul denominada Cercado Velho - CV.

Os furos são designados pelos prefixos FLM e FCV indicando a localização na área de estudo, seguido de números de identificação. Os alvos Lagoa da Mina e Cercado Velho foram objeto de sondagem em épocas distintas pela MCSA, os furos FLM foram feitos em 2010 enquanto os furos FCV foram feitos em 2012, no momento do estudo os testemunhos encontravam-se devidamente acondicionados em caixas próprias em galpão e totalizaram $2.451,96 \mathrm{~m}$ de testemunho com diâmetro médio de $6 \mathrm{~cm}$.

\section{Metodologia}

Os dados de radiação gama e de susceptibilidade magnética foram coletados diretamente nas caixas dos testemunhos de sondagem, utilizando equipamentos portáteis. A aquisição dos dados aconteceu em fevereiro de 2015 o espaçamento utilizado na coleta de dados foi de 2,0 $\mathrm{m}$ para dados de radiação gama e 1,0 $\mathrm{m}$ para a susceptibilidade magnética. $O$ tempo de exposição do testemunho ao cintilômetro adotado foi de 60 segundos.

Para as medidas da radiação gama foi utilizado um espectrômetro portátil que constitui-se de um equipamento cilíndrico multicanal formado por um detector de cintilação $\mathrm{Nal}(\mathrm{TI})$ (iodeto de sódio dopado com tálio) e um analisador de amplitude de 125 canais. $\mathrm{E}$ para as medidas de susceptibilidade foi utilizado um susceptibilimetro que utiliza um oscilador com frequência $10 \mathrm{KHz}$ em circuito LC (indutor e capacitor em paralelo), a susceptibilidade é calculada a partir da diferença de frequência entre a amostra e as medições de ar livre.

Os dados foram analisados sob dois aspectos, através de perfis geofísicos e através de análise estatística os perfis geofísicos e foram dispostos na seguinte ordem $\mathrm{K}(\%)$, U(ppm), Th(ppm), CT(nGy), litologia, Teor de cobre (\%) e susceptibilidade magnética. $\mathrm{Na}$ análise dos perfis 
geofísicos este trabalho procura identificar a relação entre o comportamento geofísico apresentado pelos testemunhos ao longo do furo, o teor de mineralização e o tipo de litologia. Tavaza (1999) sugere que há correlação entre o teor de mineralização de cobre, principalmente quando associado a ouro, com susceptibilidade magnética para depósitos relacionados a atividades hidrotermais. Os dados estatísticos foram dispostos em gráficos e matrizes de correlação.

Analises estatísticas envolvendo amostras de dados geológicos são comuns principalmente na etapa de análise de teores amostrados em furos de sondagens com o objetivo de garantir um melhor planejamento da etapa de extração do minério, Yamamoto (1992) e Ajub et al. (2003) demonstraram esta aplicação para exploração de cobre e ouro respectivamente.

\section{Resultados}

Considerando que dados geológicos e geofísicos são auferidos como consequência de processos naturais não há como o pesquisador ter controle sobre eles, desta forma para que os dados coletados possam ser tratados com métodos estatísticos válidos, apresentando resultados adequados para interpretação, nos certificamos que os dados obedeciam à distribuição de Gauss.

A distribuição normal ou Gaussiana é uma distribuição de probabilidade definida quando em grandes amostras obtidas de populações naturais existe uma frequência característica, a maioria das medidas está agrupada próxima de um valor central com declínio a partir deste ponto para ambos os lados. A figura 1 mostra 0 comportamento normal dos dados medidos para o canal de potássio.

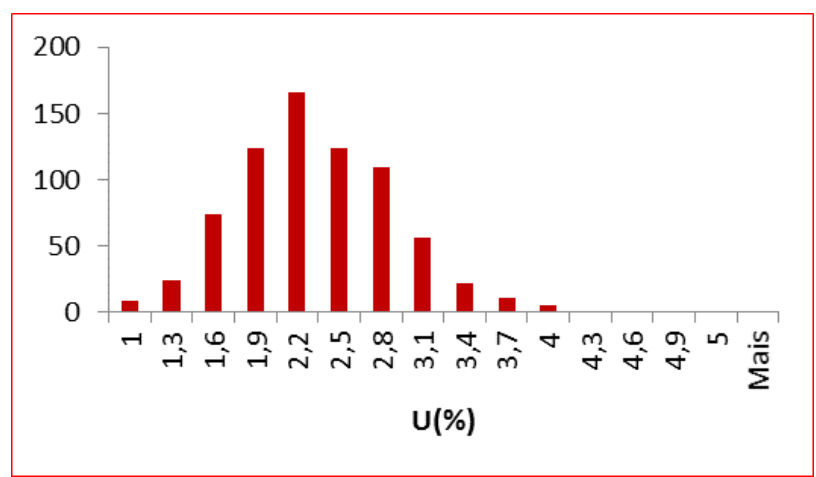

Figura 1: histograma dos dados de $K(\%)$ medidos nos testemunhos de sondagem apresentando distribuição próxima à normal.

Para verificar se existe relação entre a variação das propriedades físicas medidas nos testemunhos de sondagem e o teor da mineralização, efetuamos a análise estatística dos dados com o intuito de obtermos índices de correlação conhecidos como coeficientes de Pearson, que mede o grau de correlação entre duas ou mais variáveis. É um índice adimensional com valores situados entre -1 e 1.
A análise dos testemunhos de sondagem foi feita numericamente buscando uma correlação entre as variáveis geofísicas e o teor de mineralização de cobre através das matrizes dos coeficientes de Pearson e de forma qualitativa analisando os perfis geofísicos dos testemunhos de sondagem. A figura 2 apresenta as principais litologias catalogadas nos testemunhos de sondagem analisada. Neste trabalho serão apresentadas as matrizes de correlação e intervalos de perfis de furos que apresentaram boa correlação entre a mineralização e uma ou mais propriedades físicas analisadas. A seguir serão apresentados os furos FCV-05 e FLM-27 como exemplos de furos onde ficou o coeficiente de Pearson foi expressivo.

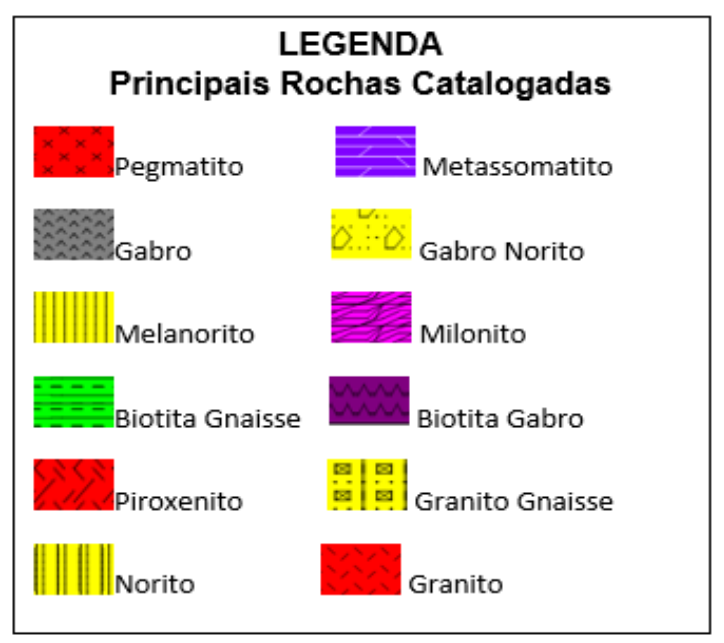

Figura 2: Principais rochas catalogadas nos testemunhos de sondagem analisados.

O FCV-05 apresenta uma boa correlação entre a susceptibilidade magnética e o teor de cobre (tabela 1). Não há correlação entre os radionuclídeos. Há picos de valores de susceptibilidade ao longo do perfil sem relação com a mineralização (figura 3).

\begin{tabular}{|c|c|c|c|c|c|c|}
\hline & CT & K & U & Th & Suscept & Cu \\
CT & 1 & & & & & \\
K & 0,594746 & 1 & & & & \\
U & 0,055689 & 0,147844 & 1 & & & \\
Th & 0,533286 & $-0,21425$ & $-0,5788$ & 1 & & \\
Suscept & $-0,46575$ & $-0,44797$ & $-0,03002$ & $-0,17133$ & 1 & \\
Cu & $-0,53955$ & $-0,16413$ & $-0,20474$ & $-0,36435$ & 0,547282 & 1 \\
\hline
\end{tabular}

Tabela 1: Coeficientes de correlação do furo FCV-05 

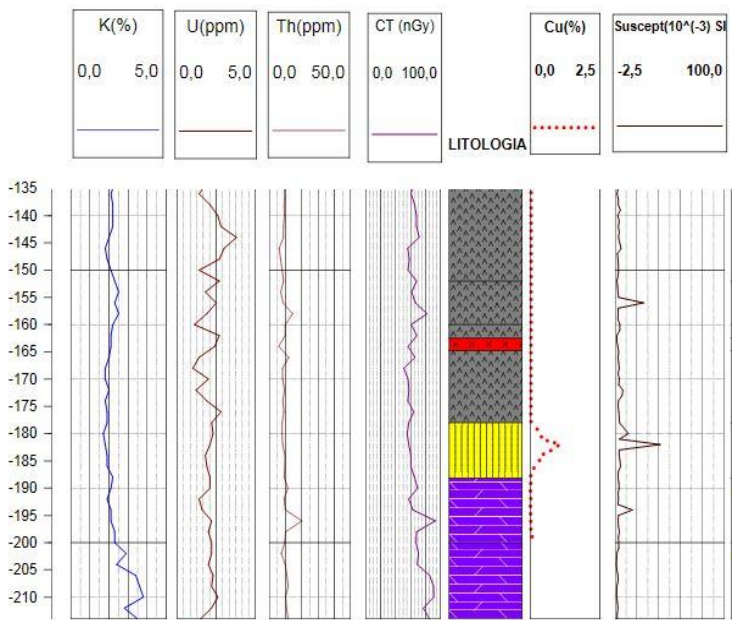

Figura 3: Recorte do perfil geofísico do testemunho do furo FCV-05 no intervalo de profundidade de 100 a 210 metros.

A análise dos coeficientes de correlação do FLM-27 indica haver uma boa correlação entre a susceptibilidade magnética e o teor de mineralização (tabela 2) e entre este e o tório. A mineralização ocorre nos intervalos de 25 a $30 \mathrm{~m}$ onde a litologia é dominada por biotita gnaisse com valores de susceptibilidade chegando a $100.10^{-2} \mathrm{SI}$ e entre 70 e $75 \mathrm{~m}$ onde a litologia é melanorito, neste último intervalo ocorre os maiores valores de teor de cobre do furo, há um novo pico no valor da susceptibilidade (figura 4), mas de menor intensidade.

\begin{tabular}{|c|c|c|c|c|c|c|}
\hline & CT & K & U & Th & Suscept & Cu \\
CT & 1 & & & & & \\
K & 0,649934 & 1 & & & & \\
U & 0,259423 & $-0,13997$ & 1 & & & \\
Th & 0,644788 & 0,158328 & $-0,28699$ & 1 & & \\
Suscept & $-0,59877$ & $-0,1227$ & $-0,37247$ & $-0,38586$ & 1 & \\
Cu & 0,06638 & 0,197336 & $-0,91977$ & $\mathbf{0 , 6 2 8 8 4}$ & $\mathbf{0 , 4 7 8 5 6 4}$ & 1 \\
\hline
\end{tabular}

Tabela 2: Coeficientes de correlação do furo FLM-27
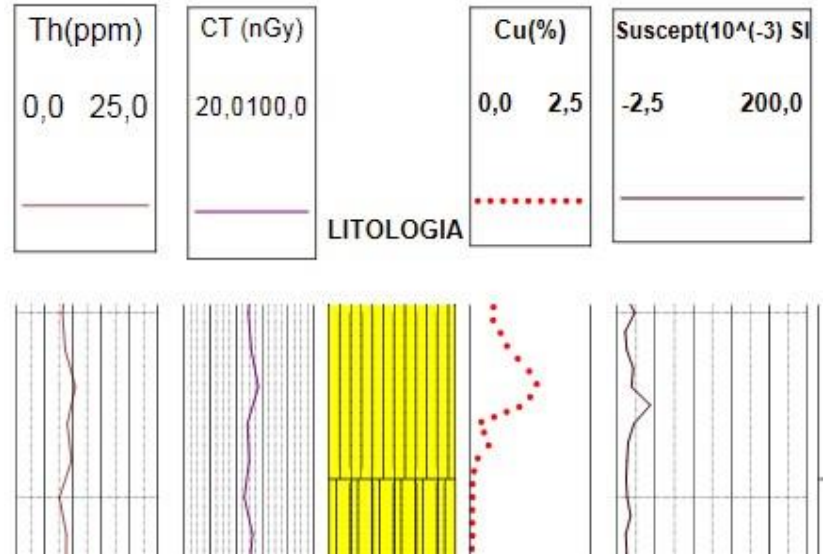

Figura 4: Recorte do perfil geofísico do furo FLM-27 no intervalo de profundidade entre 70 e 80 metros.
Dos 18 furos analisados 12 apresentaram correlação positiva entre a susceptibilidade magnética e o teor de cobre (considerando teores maiores ou iguais a $0,1 \%$ ). Apenas 4 furos apresentaram coeficientes de correlação classificados como médio ou grande. Os valores da espectrometria gama variaram pouco e mantiveram-se baixos, de certa forma esperados devido ao fato de as rochas hospedeiras da mineralização serem rochas básicas, conhecidamente fracas portadoras de isótopos de potássio, uranio e tório.

De maneira geral, os valores de susceptibilidade magnética medidos foram relativamente baixos, indicando que a mineralização nos alvos Lagoa da Mina e Cercado Velho podem não estar associadas à forte presença de magnetita, como ocorre em depósitos de sulfetos mais simples, haja vista que os valores medidos se concentram entre o e $100 \times 10^{-3}$ (figura 5) com poucas ocorrências de medidas de valores próximos ao esperado para a magnetita $(\gg 1)$.

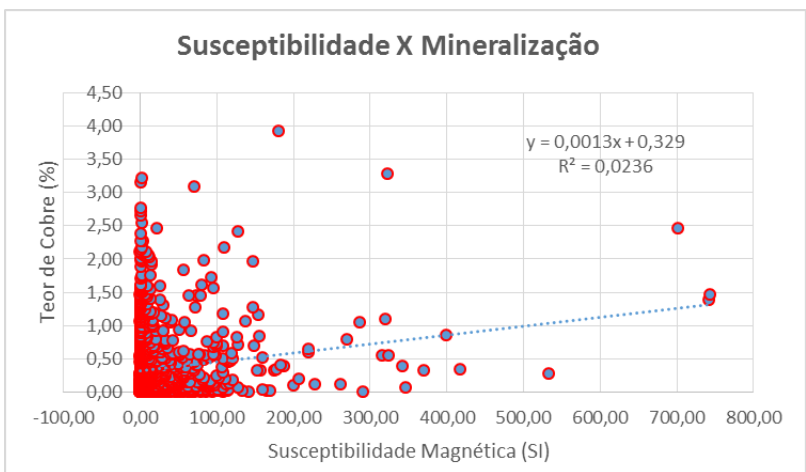

Figura 5: Gráfico da dispersão da susceptibilidade magnética $X$ teor de cobre para as amostras dos 18 furos analisados.

\section{Discussão e Conclusões}

Analisando os perfis geofísicos gerados na realização deste trabalho verificou-se que não há correlação entre os valores das concentrações medidas dos radioisótopos e o teor de mineralização nos testemunhos de sondagem. Os teores médios de $\mathrm{K}(\%)$ variam em torno de $2,02 \%$ estando levemente acima da média para a crosta superior. No entanto, os teores médios de Th(ppm) e U(ppm) encontram-se abaixo da média, medindo 9,26 ppm e 2,29 ppm, respectivamente.

Em alguns momentos o teor de radioisótopos varia positivamente com a mineralização, mas estas variações correm de forma extremamente pontual e parece estarem associadas a alterações hidrotermais locais. As medidas de susceptibilidade magnética mostram-se baixas nos testemunhos e pontualmente variam para valores relativamente altos. A mineralização apresenta correlação com a susceptibilidade magnética, embora ocorram picos de susceptibilidade sem necessariamente estarem associados a bons teores de mineralização em outras amostras ocorrem bons teores de mineralização sem a associação com alta susceptibilidade. 
Verificou-se não haver correlação entre os teores radioativos e a mineralização. Os valores de susceptibilidade magnética auferidos nos testemunhos são extremamente baixos, há uma correlação com a mineralização.

\section{Agradecimentos}

Os autores agradecem à Mineração Caraíba S.A pela disponibilização dos dados geológicos e de teor de cobre nos testemunhos e por ter proporcionado a estrutura para a coleta dos dados geofísicos utilizados neste trabalho.

\section{Referências}

Ajub, R. R. E., Cintra, E. C. e Sturaro, J. R. 2003. Comparação de Amostragens em Sondagens Rotativas Diamantadas com Sondagens Tricônicas de Circulação Reversa em uma Pesquisa Mineral. Revista Instituto de Geociências da Universidade do Estado de São Paulo, Rio Claro, vol. 22:95-103.

D'el Rey Silva L. J. H. 1984. Geologia e Controle Estrutural do Depósito Cuprífero, Vale do Curaçá, Bahia, Brasil. Dissertação (mestrado). Instituto de Geociências, Universidade Federal da Bahia. Salvador. 208p.

Delgado, I. M e Souza, J. D. 1975. Projeto Cobre-Curaçá: Relatório Final, Geologia Econômica do Distrito Cuprífero do Rio Curaçá, Bahia, Brasil. Salvador. CPRM. 30v. $419 p$.

Tavaza, E. 1999. Mineralização de Au-Cu( \pm Etr-U) Associada à Brechas Hidrotermais do Depósito de Igarapé Bahia, Provincia Mineral de Carajas, Pará. Dissertação (mestrado), Escola de Minas, Universidade Federal de Ouro Preto, Ouro Preto, 107p.

Teixeira, L. R. (1997). O Complexo Caraíba e a Suíte São José do Jacuípe no Cinturão Salvador-Curaçá (Bahia, Brasil): Petrologia, Geoquímica e Potencial Metalogenético. Tese (doutorado). Universidade Federal da Bahia. Salvador. 188 p.

Yamamoto, J. K. 1999. Análise Estatística dos Dados de Furos de Sondagem da Jazida de Cobre de Chapada, Goias Revista do Instituto de Geociências da Universidade de São Paulo, São Paulo, vol. 13:31-45. 